\title{
Antioxidant and anti-inflammatory dietary supplements in the treatment of osteoarthritis: a scoping review
}

\author{
${ }^{1}$ Ong, Y.Q., ${ }^{1, *}$ Sakinah, H., ${ }^{1}$ Shahril, M.R. and ${ }^{2}$ Norshazila, S. \\ ${ }^{1}$ School of Nutrition and Dietetics, Faculty of Health Sciences, Universiti Sultan Zainal Abidin, Gong Badak \\ Campus, 21300 Kuala Nerus, Terengganu, Malaysia \\ ${ }^{2}$ School of Food Industry, Faculty of Bioresources and Food Industry, Universiti Sultan Zainal Abidin, \\ Besut Campus, 22200 Besut, Terengganu, Malaysia
}

\section{Article history:}

Received: 12 May 2019

Received in revised form: 22 July 2019

Accepted: 26 July 2019

Available Online: 5 Aug 2019

\section{Keywords:}

Antioxidant,

Anti-inflammatory,

Dietary supplement,

Osteoarthritis

DOI:

https://doi.org/10.26656/fr.2017.4(2).189

\begin{abstract}
The increasing number of evidence has reported inflammation and oxidative stress as key mediators of osteoarthritis (OA) joint pathology. Therefore, the usage of dietary supplements targeting inflammation and oxidative stress in OA may emerge as a rewarding therapeutic strategy. This study aimed to explore the efficacy of antioxidant and anti-inflammatory dietary supplements used to manage OA. A methodological framework proposed by Arksey and O'Malley was used to conduct this scoping review. An electronic database search of English academic articles was conducted using PubMed, MEDLINE and ScienceDirect from 2000 to 2018. Randomized controlled trials (RCTs) of OA with parallel groups by comparing dietary supplements with placebo consumption were eligible for inclusion. Out of 69,150 studies identified, a total of 41 studies were included, with 25 antioxidant or anti-inflammatory dietary supplements identified. There were 3325 respondents (1740 in the treatment group and 1585 in the placebo group), all aged $\geq 25$ years old and comprised of $69.6 \%$ and $30.4 \%$ female and male respondents, respectively. The majority of the studies recruited participants with knee OA $(n=33)$ with a follow-up duration of 3 to 32 weeks. Overall, most of the dietary supplements $(n=17)$ demonstrated a beneficial effect on the clinical signs and symptoms, such as Boswellia serrata extract (BSE), Pycnogenol and L-carnitine. In contrast, Aquamin supplementation did not exert positive impacts on OA management, while inconsistent findings were observed in greenlipped mussel (GLM) extract, vitamin E, methylsulfonylmethane (MSM), licorice flavonoid oil (LFO), ginger, willow bark extract and rose hip supplementation. In summary, the role of anti-inflammatory and antioxidant dietary supplements cannot be ignored as they can offer alleviated pain and symptom relief.
\end{abstract}

\section{Introduction}

Osteoarthritis (OA) is a progressive joint disease that is attributed to a biochemical or genetic factor (Ministry of Health, 2013). OA is characterized by the degeneration and loss of articular cartilage accompanying the synovial inflammation, which is associated with pain (Doherty et al., 2016). It is the most prevalent form of arthritis (Bijlsma et al., 2011) and a major cause of disability worldwide (Conaghan et al., 2014). It can occur in various joints, such as hip, knee and hand, whereby knee osteoarthritis (KOA) is more common (Zhang and Jordan, 2010).

The incidence of $\mathrm{OA}$ is becoming more prevalent due to the increasing number of elderly and obesity cases (Neogi and Zhang, 2013; Nur Aimi et al., 2018). It is expected that OA will contribute to an increased burden due to the aging population and unhealthy lifestyle (Belcaro et al., 2008b). According to Woolf and Pfleger (2003), 9.6\% of men and $18.0 \%$ of women aged over 60 years have symptomatic OA, with $25.0 \%$ of them being unable to carry out routine daily activities.

Recently, the use of paracetamol and non-steroidal anti-inflammatory drugs (NSAIDs) as the first-line medication has been questioned due to their adverse side effects, such as increased risk of peptic ulcers and upper gastrointestinal bleeding (da Costa et al., 2017). Thus, this prompts the patients to find alternative treatments, with dietary supplements or non-pharmacological supplements usage emerging as a complementary or alternative treatment for OA patients (Green et al., 2014). 
$\mathrm{OA}$ is no longer viewed as a mere wear-and-tear problem (Rosenbaum et al., 2010). On the contrary, there is increasing evidence highlighting inflammation and oxidative stress as the key mediators of OA joint pathology, suggesting the use of dietary supplements targeting these elements in $\mathrm{OA}$ to be a potentially rewarding therapeutic strategy (Philp et al., 2016). Hence, this review aimed to explore further on the efficacy of antioxidant and anti-inflammatory dietary supplements used to manage OA.

\section{Materials and method}

The present study was designed as a scoping review, which investigated the efficacy of antioxidant and antiinflammatory dietary supplements used to manage OA. The five-stage methodological framework outlined by Arksey and O'Malley (2005) was used as a guideline for the scoping review, which consisted of: (1) identifying the research questions; (2) identifying the relevant studies; (3) selecting studies; (4) charting the data; and (5) collating, summarizing and reporting the results. The Preferred Reporting Items for Systematic Reviews and Meta-Analysis (PRISMA) flow diagram illustrated the flow of articles from the search to its final selection as shown in Figure 1 (Moher et al., 2009).

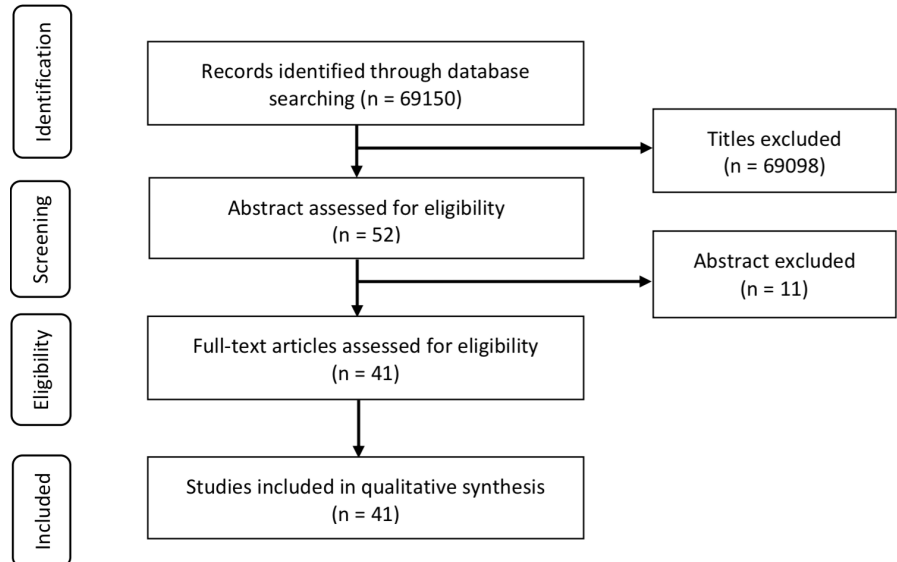

Figure 1. Preferred Reporting Items for Systematic Reviews and Meta-Analysis (PRISMA) flow diagram of study selection

\subsection{Identifying the research questions}

The review questions were: (1) what types of antioxidant and anti-inflammatory dietary supplements and their active ingredients are used among OA patients?; and (2) what is the efficacy of antioxidant and anti-inflammatory dietary supplements used to manage $\mathrm{OA}$ ?

\subsection{Identifying relevant studies}

Academic journals (English) published from 2000 to 2018 were identified by conducting electronic databases search using PubMed, MEDLINE and ScienceDirect. All RCTs with parallel groups, excluding systematic reviews or review papers, were included in the search. Titles, abstracts and keywords were examined independently for eligibility by the researchers. A total of 41 studies were included in this review from 69,150 studies identified through the electronic databases search. Key search terms used to search the articles are displayed in Table 1 below.

Table 1. Key search terms in the scoping review

Antioxidant OR Anti-inflammatory supplements AND

Dietary supplements OR Nutraceuticals AND Osteoarthritis

Omega-3 fatty acids OR Fish oil AND Osteoarthritis

Krill Oil AND Osteoarthritis

Green-lipped mussel extract OR Perna canaliculus AND Osteoarthritis

Vitamin E OR Tocopherol OR Tocotrienol AND Osteoarthritis Willow bark extract AND Osteoarthritis

Methylsulfonylmethane AND Osteoarthritis

Avocado/soybean unsaponifiables AND Osteoarthritis

Boswellia serrata extract OR Aflapin OR 5-Loxin AND Osteoarthritis

Pine bark extract OR Pycnogenol AND Osteoarthritis

Vitamin C OR Ascorbic acid AND Osteoarthritis

L-carnitine AND Osteoarthritis

Artemisia annua extract AND Osteoarthritis

Deer bone extract AND Osteoarthritis

Garlic Or Allium sativum AND Osteoarthritis

Bitter Melon Or Momordica charantia AND Osteoarthritis

Argan oil AND Osteoarthritis

Liquorice flavonoid oil AND Osteoarthritis

Ginger OR Zingiber officinale AND Osteoarthritis

Pomegranate AND Osteoarthritis

Sesame seed AND Osteoarthritis

Russian olive AND Osteoarthritis Phytalgic AND Osteoarthritis

Calcium fructoborate AND Osteoarthritis

Aquamin AND Osteoarthritis

Soy protein AND Osteoarthritis

Rose hip AND Osteoarthritis

Turmeric or Curcumin AND Osteoarthritis

Beta-carotene OR Vitamin A AND Osteoarthritis

Purple passion fruit peel extract AND Osteoarthritis

\subsection{Selecting studies}

Studies were eligible for inclusion in this review should they meet the following inclusion criteria: (1) patients diagnosed with $\mathrm{OA}$ and had not undergone surgery; (2) reported outcomes, such as pain, physical function, stiffness, quality of life, and pain medication usage; and (3) evaluated the efficacy of individual dietary supplements.

\subsection{Charting the data}

The data presented were author(s), year of publication, country, study design, types of supplement and its active ingredients, participants' characteristics, outcomes reported, and results displayed in mean \pm standard deviation and p-value, which were relevant to 
the review.

\subsection{Collating, summarizing and reporting the results}

Findings of the review on the efficacy of antioxidant and anti-inflammatory dietary supplements used to manage OA were presented.

\section{Results}

\subsection{Study characteristics}

From the 41 studies included, a total of 25 antioxidant or anti-inflammatory dietary supplements were identified. The research evidence on the efficacy of these dietary supplements is summarized in Supplementary Table 2 . The total number of respondents were 3325 (1740 in the treatment group and 1585 in the placebo group), all of which aged $\geq 25$ years old. There were more female participants compared to male (69.6\%:30.4\%). Patients' population in studies done by Dehghani et al. (2018), Malek Mahdavi, Mahdavi, and Kolahi (2016), Malek Mahdavi et al. (2015) and Salimzadeh et al. (2018) included only females. Only one study did not provide information regarding the gender sampled (Eftekhar Sadat et al., 2013). The majority of the studies recruited participants with knee OA $(n=33)$. Meanwhile, six studies involved participants with either knee or hip OA (Schmid et al., 2001; Warholm et al., 2003; Jacquet et al., 2009; Ginnerup-Nielsen et al., 2015; Hunt et al., 2016; Stebbings et al., 2017), whereas three studies did not state the affected OA region (Belcaro et al., 2008a; Belcaro et al., 2010). The follow-up duration for the included studies ranged from 3 to 32 weeks. The followup duration was classified into three categories, namely short term ( $\leq 12$ weeks), medium term (12 to 24 weeks), and long term (> 24 weeks) (Liu et al., 2018). Most of the studies were conducted within a short term duration $(n=35)$, while five studies followed up in the medium term duration (Brand et al., 2001; Warholm et al., 2003; Lau et al., 2004; Srivastava et al., 2016; Kinoshita et al., 2017) and only one study followed up in the long term duration (Gianni Belcaro et al., 2010).

Eight studies were conducted in European countries (Appelboom et al., 2001; Schmid et al., 2001; Warholm et al., 2003; Cisár et al., 2008; Belcaro et al., 2008a; Jacquet et al., 2009; Belcaro et al., 2010; GinnerupNielsen et al., 2015), five studies in the United States of America (Altman and Marcussen, 2001; Arjmandi et al., 2004; Kim et al., 2006; Frestedt et al., 2009; Pietrzkowski et al., 2014), four in Oceanian countries (Brand et al., 2001; Farid et al., 2010; Hunt et al., 2016; Stebbings et al., 2017) and one study conducted in Africa country (Essouiri et al., 2017). The remaining 23 studies were conducted in Asian countries. All of the studies included were single-center double-blind RCTs, excluding one study of single-center single-blind RCT (Lim et al., 2018), one study of multicenter double-blind RCT (Altman and Marcussen, 2001), two studies of single-center double-blind prospective study (Debbi et al., 2011; Nakagawa et al., 2014), and two multicenter double-blind prospective studies (Appelboom et al., 2001)

\subsection{Dietary supplements with positive results}

Overall, out of 25 dietary supplements identified, 17 of them demonstrated beneficial effect on clinical signs and symptoms. These dietary supplements were krill oil (Suzuki et al., 2016), avocado/soybean unsaponifiables (ASU) (Appelboom et al., 2001), curcumin (Gianni Belcaro et al., 2010; Nakagawa et al., 2014; Panahi et al., 2014; Srivastava et al., 2016), BSE (Sengupta et al., 2008; Sengupta et al., 2010; Vishal et al., 2011), Pycnogenol (Belcaro et al., 2008a; Cisár et al., 2008; Farid et al., 2007), purple fruit passion peel (PFP) extract (Farid et al., 2010), L-carnitine (Malek Mahdavi et al., 2015; Malek Mahdavi, Mahdavi and Kolahi, 2016), Artemisia annua (ART) extract (Hunt et al., 2016), deer bone extract (DBE) (Shin et al., 2018), garlic (Dehghani et al., 2018; Salimzadeh et al., 2018), Momordica charantia (Lim et al., 2018), argan oil (Essouiri et al., 2017) pomegranate juice (PJ) (Ghoochani et al., 2016), sesame seed (Eftekhar Sadat et al., 2013), Phytalgic ${ }^{\circledR}$ (Jacquet et al., 2009), soy protein (Arjmandi et al., 2004) and calcium fructoborate (CFB) (Pietrzkowski et al., 2014)

\subsection{Dietary supplements with negative results}

Frestedt et al. (2009) reported that Aquamin supplementation is ineffective in symptoms of improvement among OA patients.

\subsection{Dietary supplements with mixed results}

Inconsistent findings were observed in GLM extracts (Lau et al., 2004; Stebbings et al., 2017), vitamin E (Brand et al., 2001; Tantavisut et al., 2017), MSM (Kim et al., 2006; Debbi et al., 2011), rose hip (Warholm et al., 2003; Ginnerup-Nielsen et al., 2015), LFO (Kinoshita et al., 2017), ginger (Alipour et al., 2016; Altman and Marcussen, 2001; Niempoog et al., 2012; Zakeri et al., 2011) and willow bark extract (Schmid et al., 2001).

\section{Discussion}

Recent evidence suggested that inflammation (Lei et al., 2017) and oxidative stress (Chin and Ima-Nirwana, 2018) are involved in the underlying mechanism leading to the cartilage degradation in OA. Not surprisingly, OA 


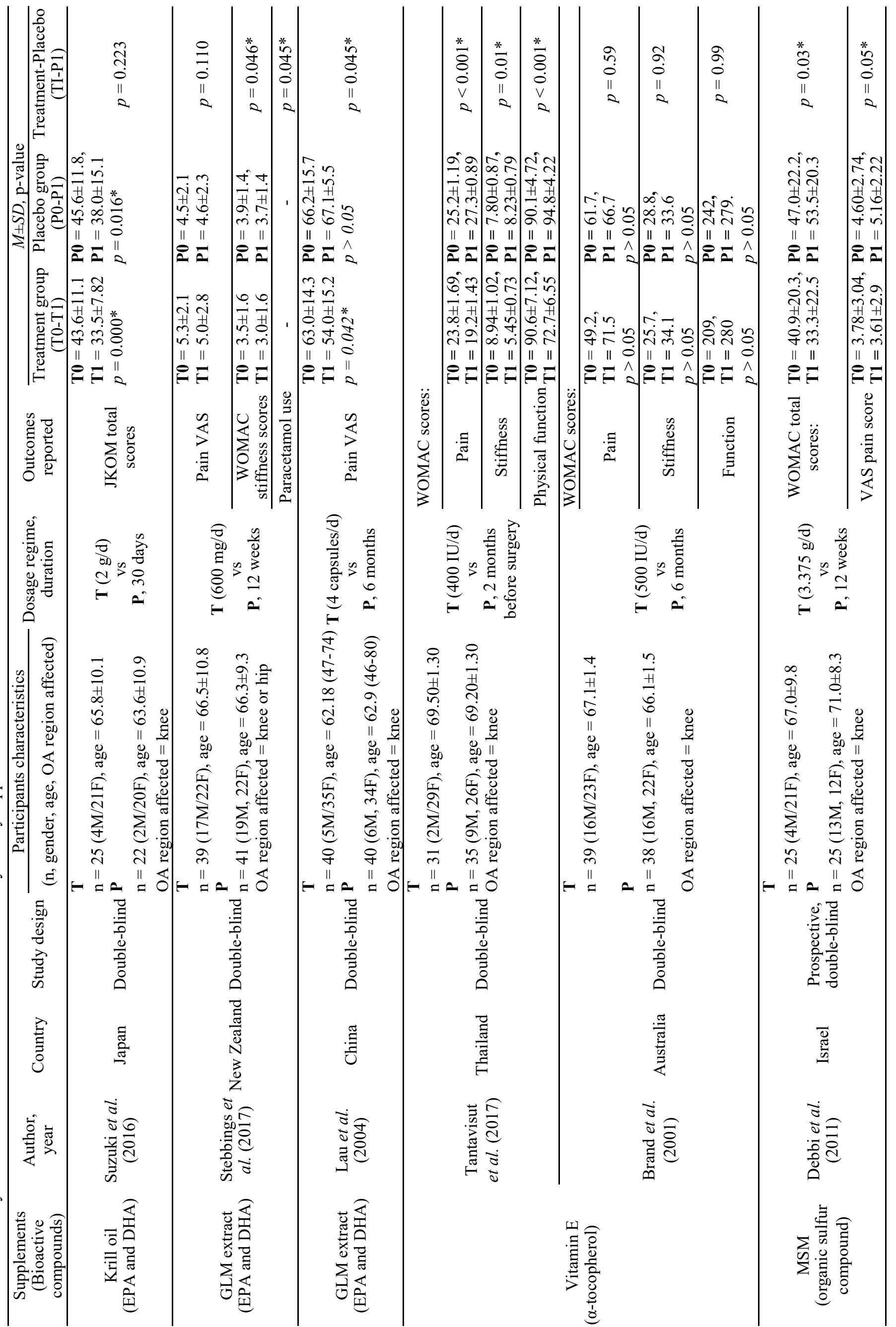




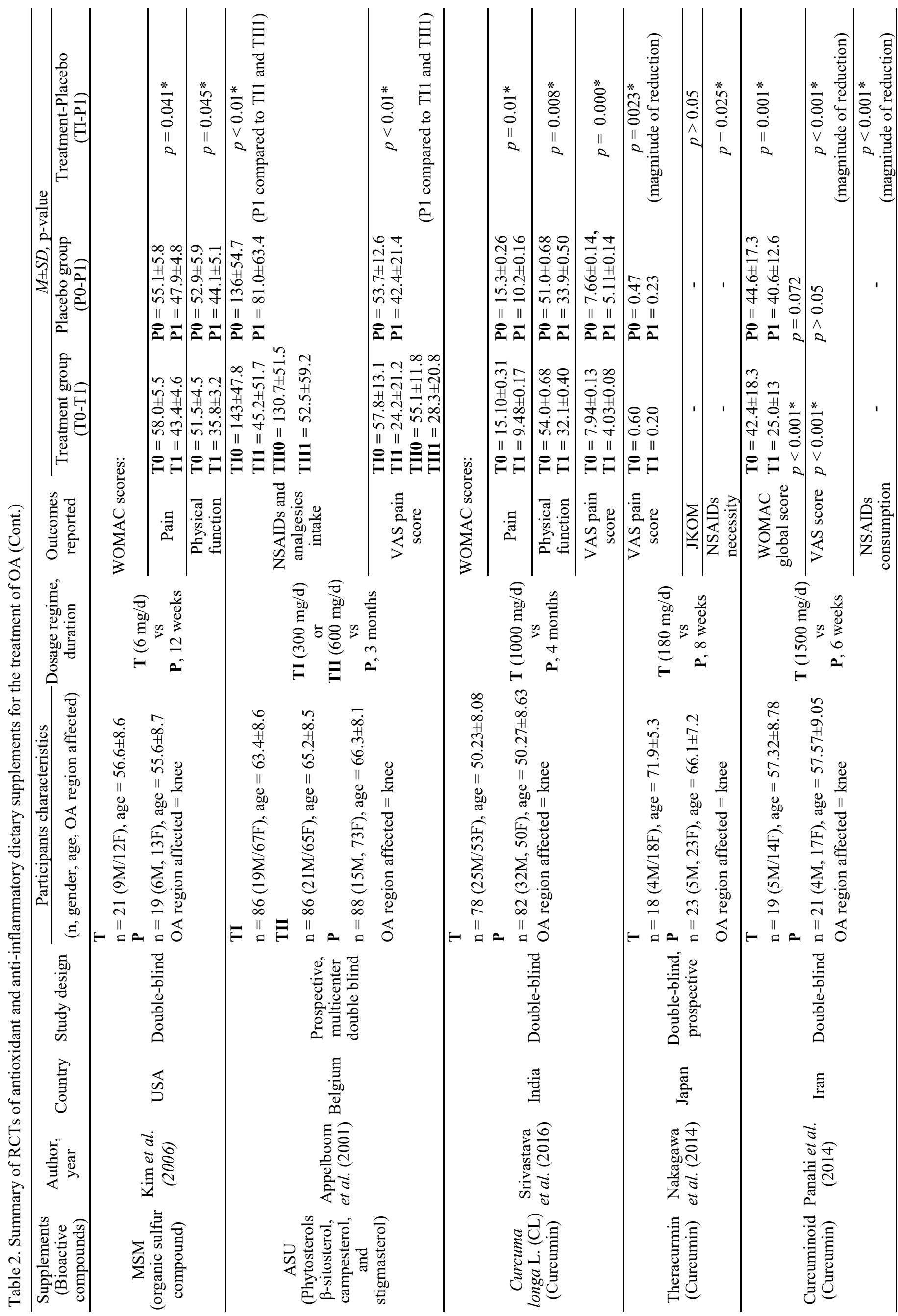




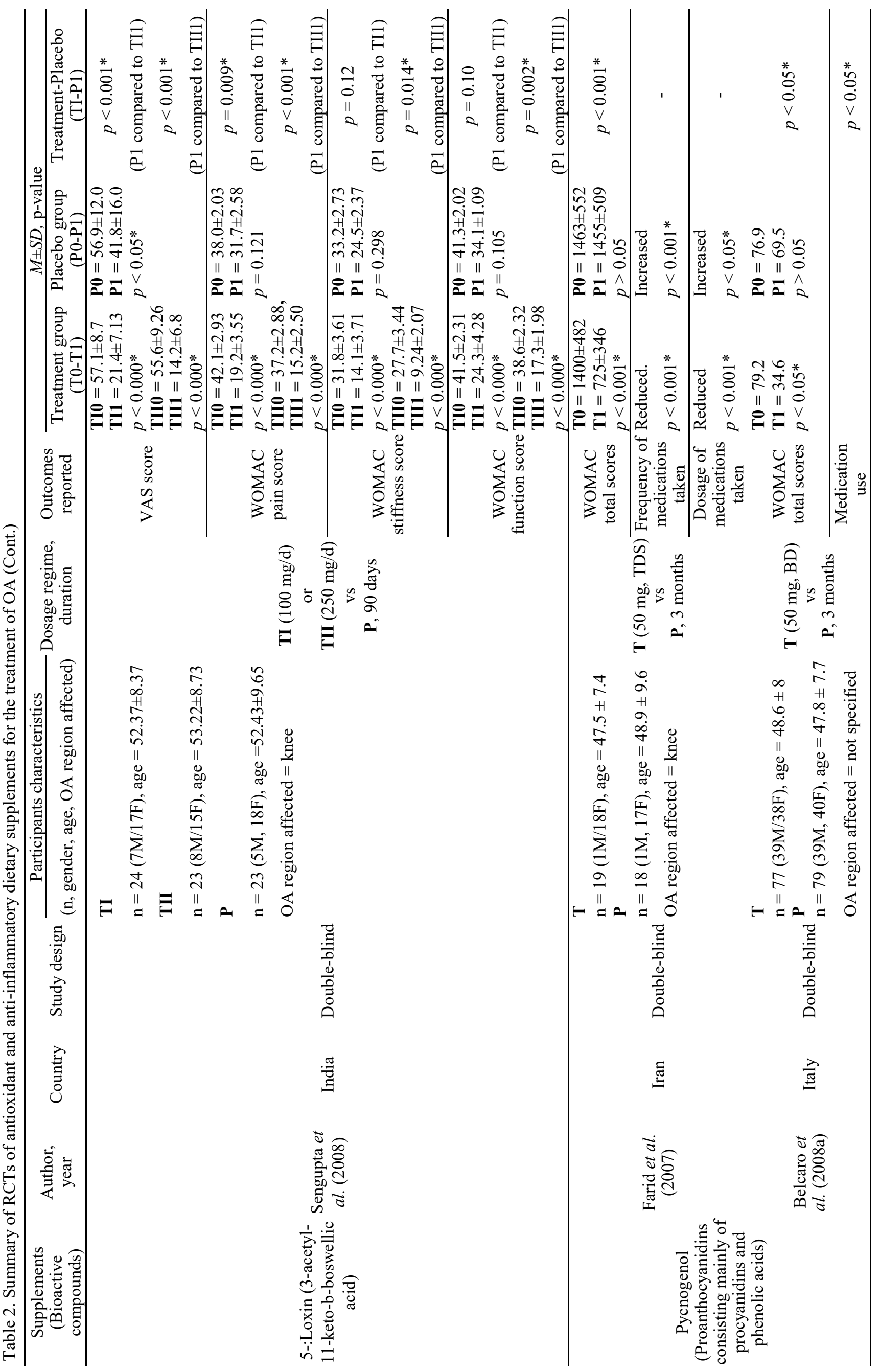



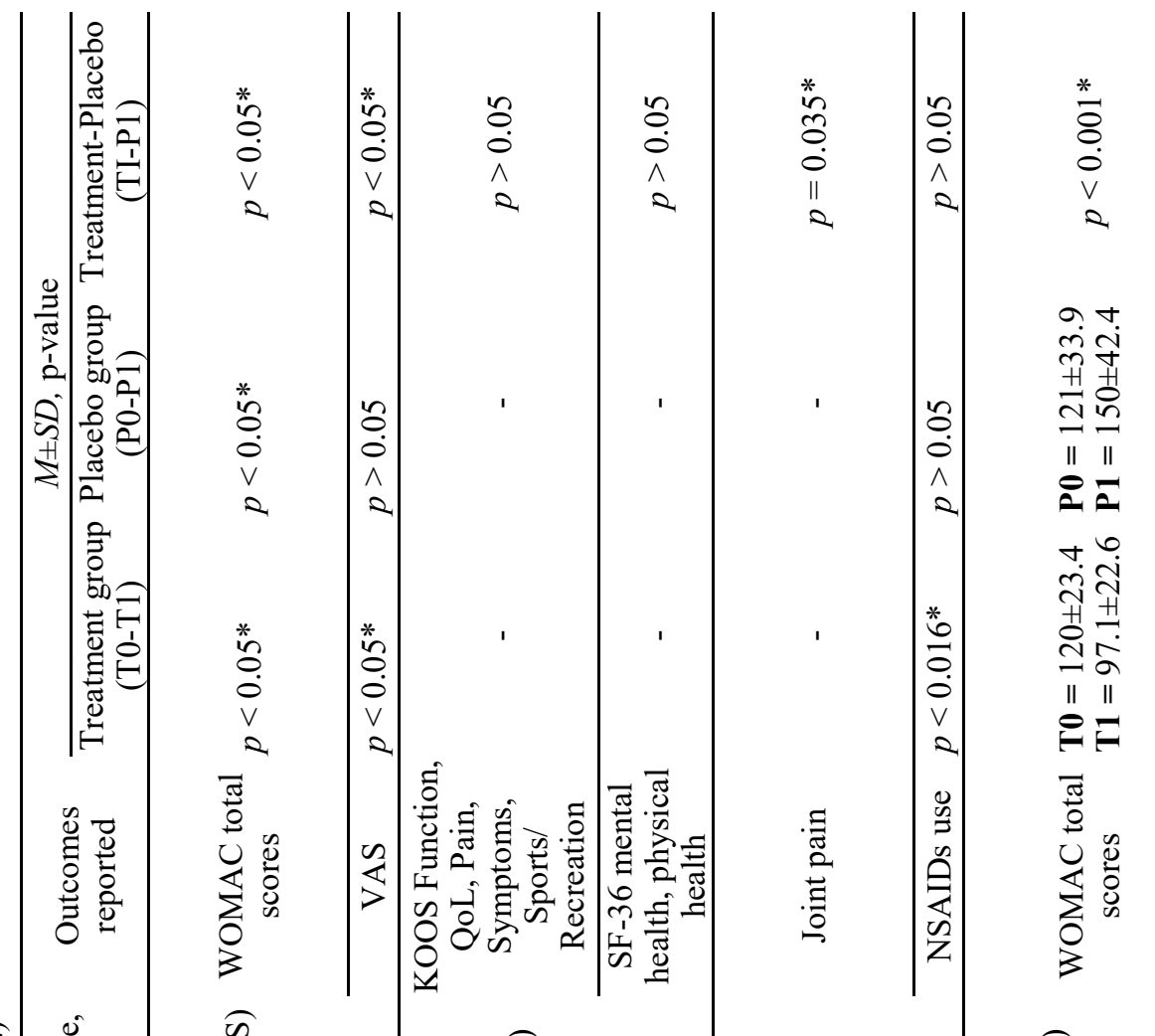

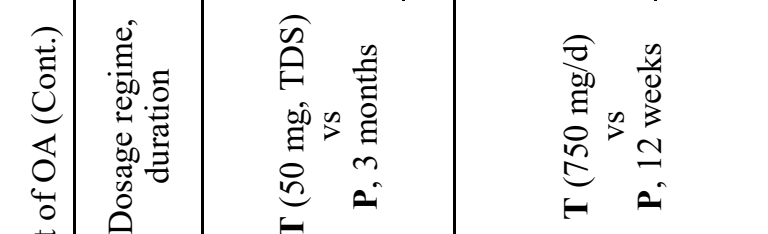
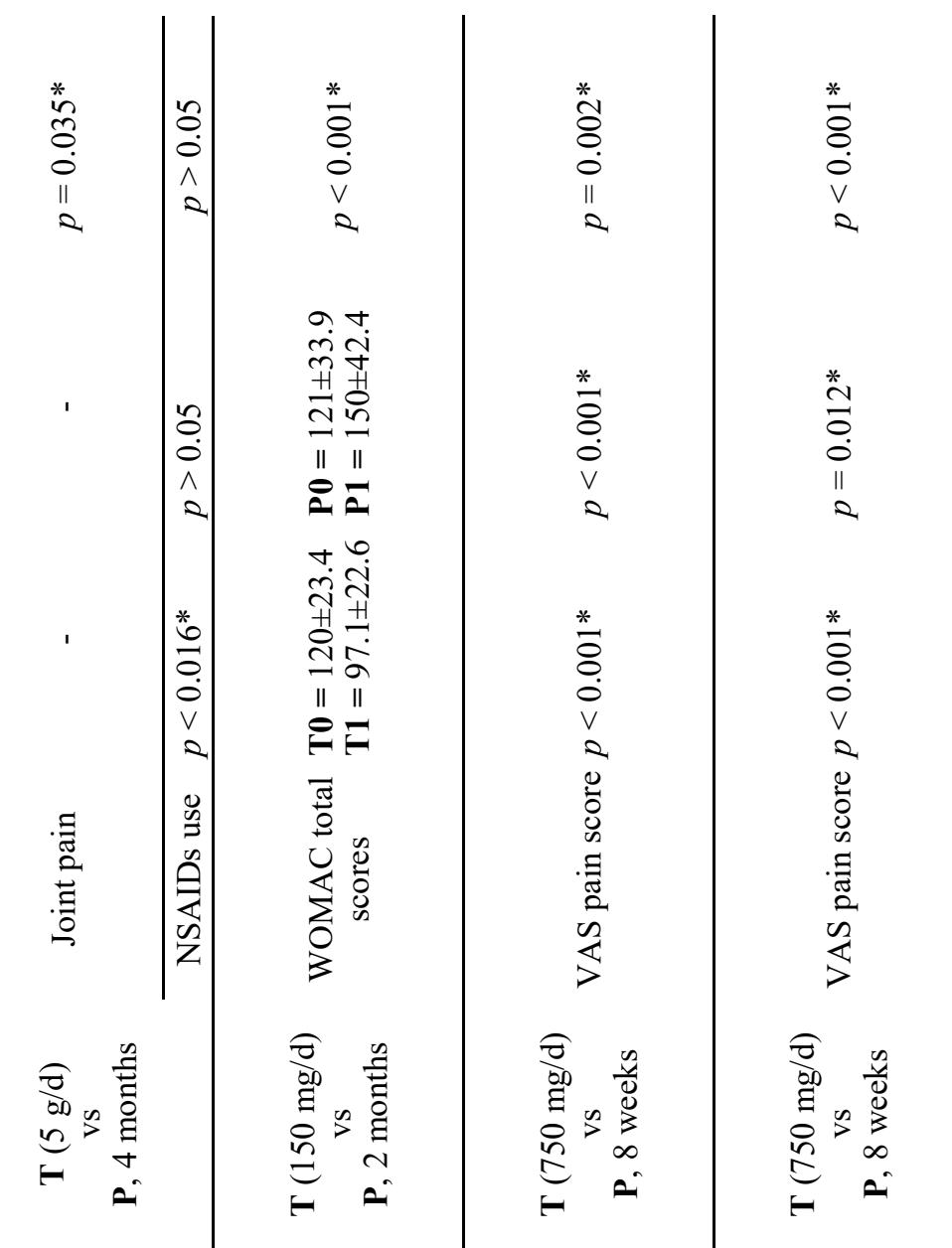

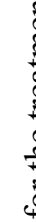

(ิ)

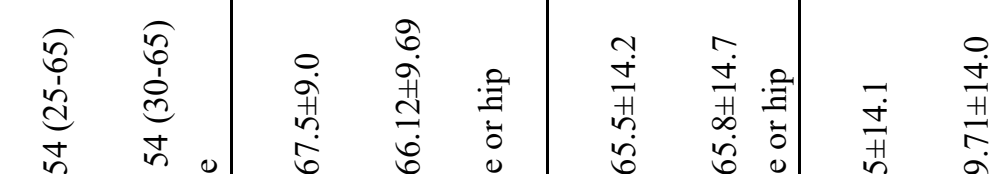

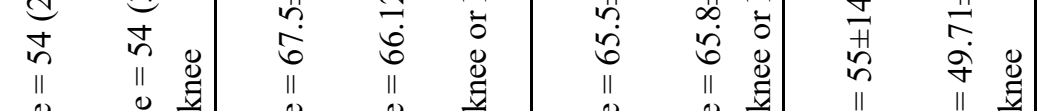

aे in

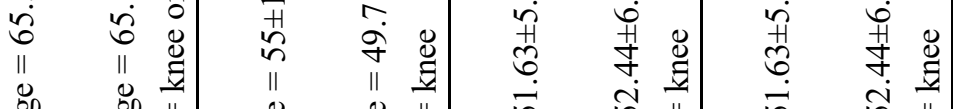

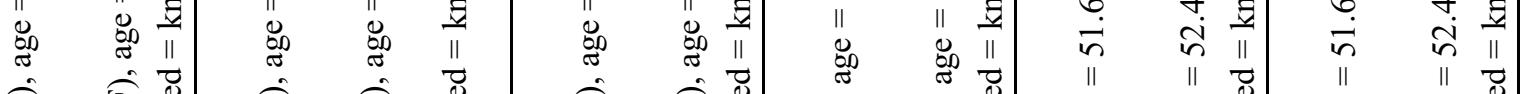

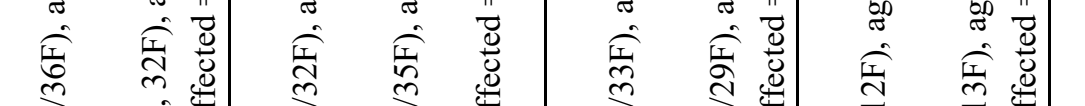

$\begin{array}{lllllll}\| & \| & \overrightarrow{0} & \| & \| & \overrightarrow{0} \\ 0 & 0 & 0 & 0 & 0 & 0\end{array}$

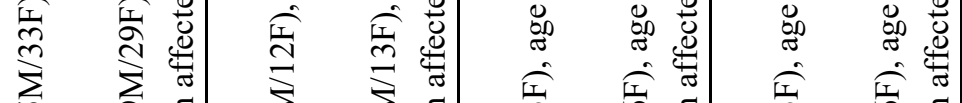

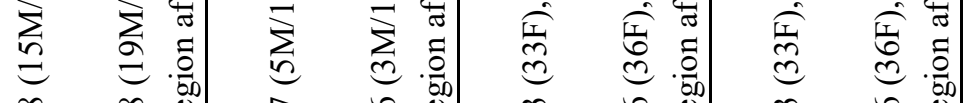

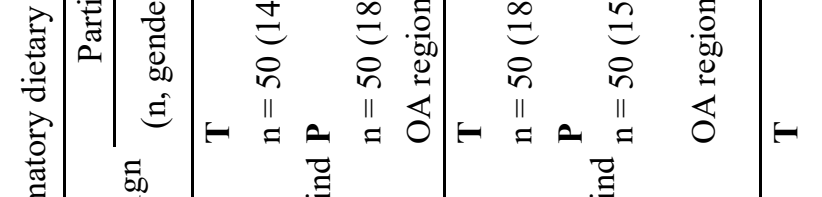

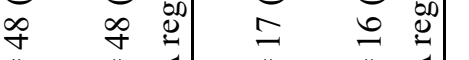

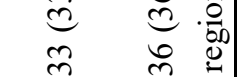

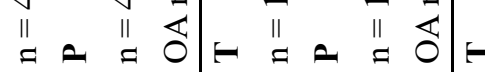

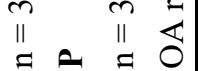
m .

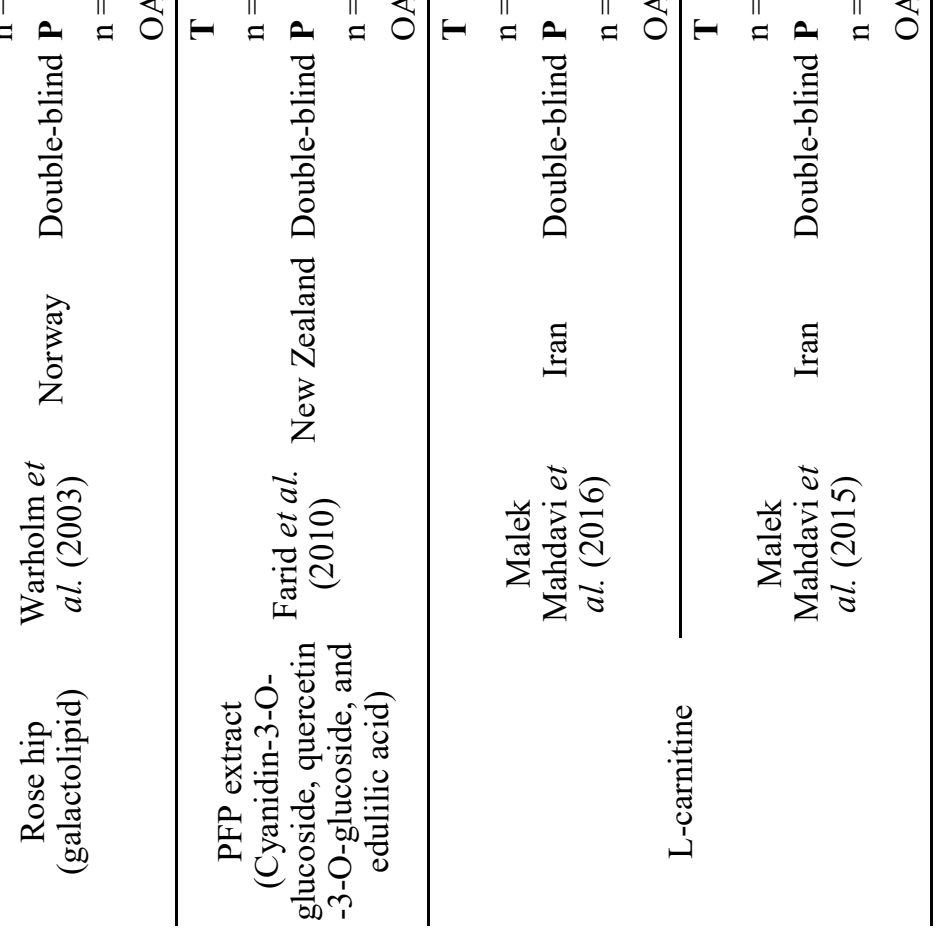




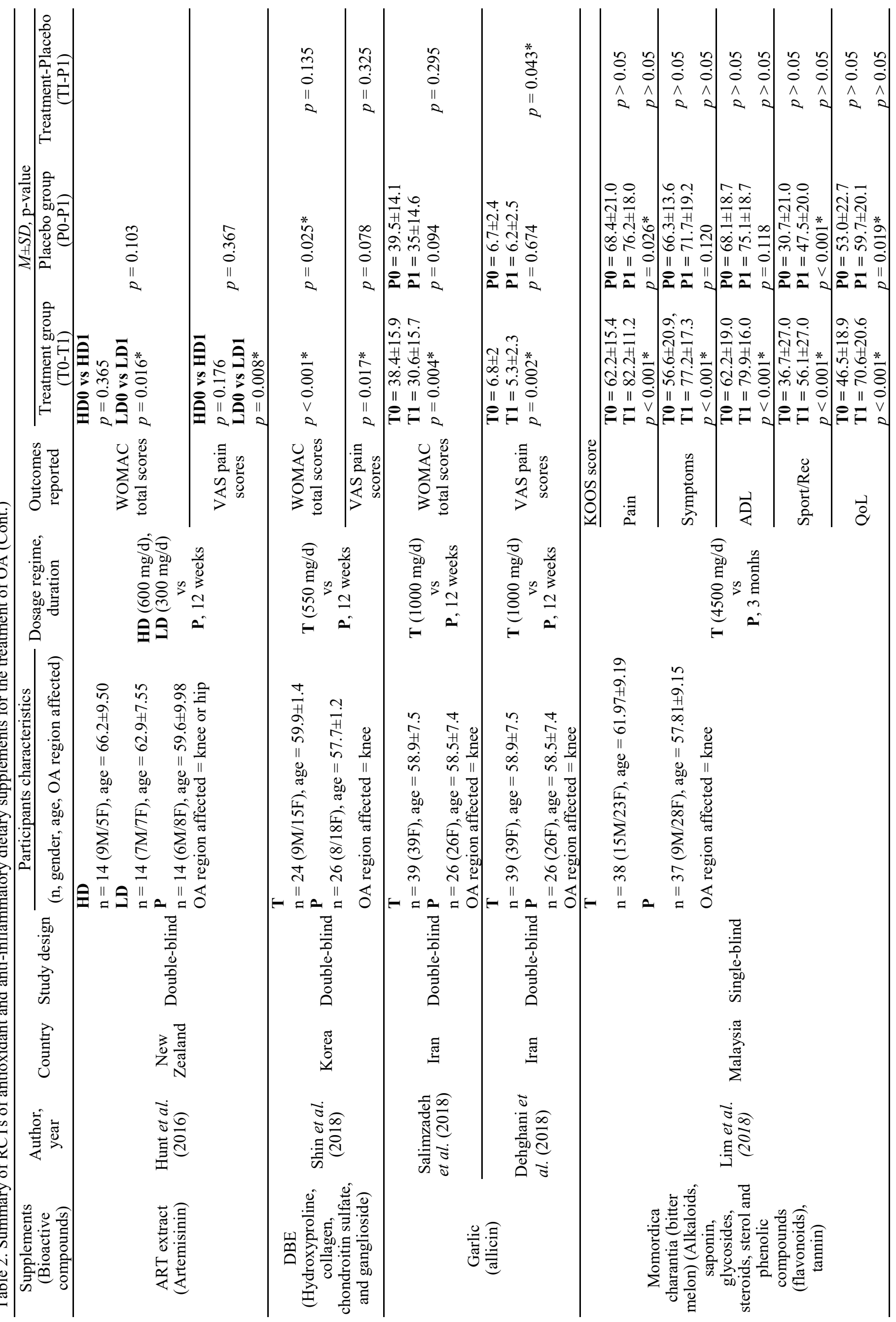




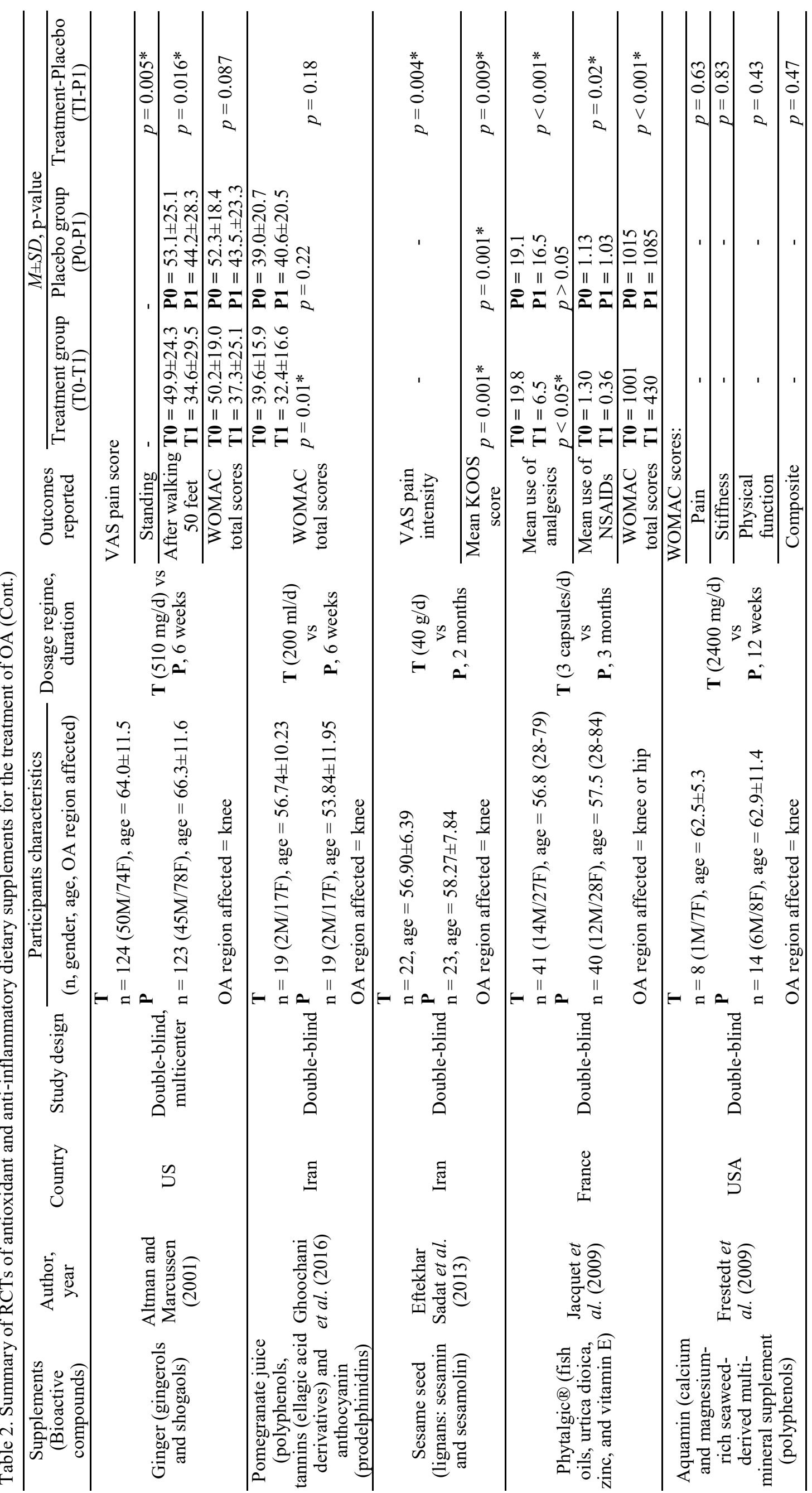




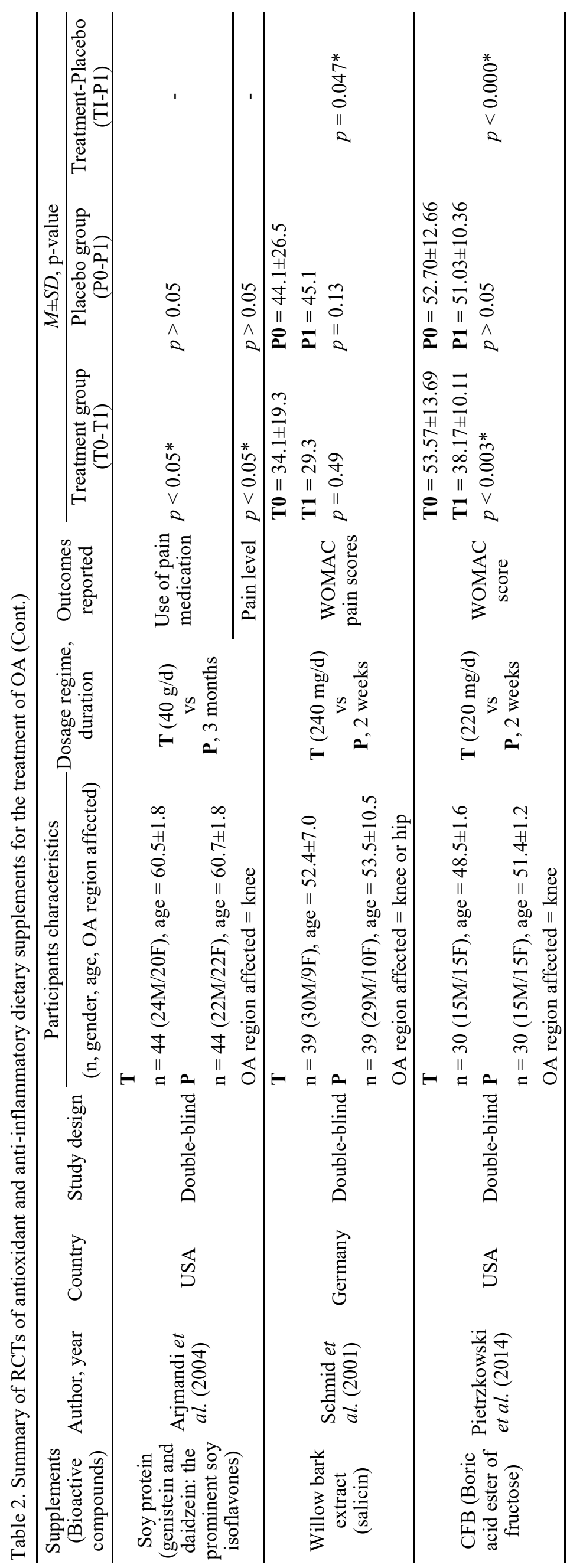


affects the whole joint by destroying the articular cartilage, altering the underlying subchondral bone structure, and inducing the chronic inflammation of synovium (Ashford and Williard, 2014). The destruction of articular cartilage results in reduced capability to distribute a large burden and minimize friction between the joint spaces. Subsequently, a bone will come in contact with an opposing bony surface directly due to reduced joint space. Over time, new osteophytes will be formed, which generate a chronic inflammatory process in which cytokines and matrix metalloproteinases (MMP) are released into the joint (Birrell and Oliver, 2010).

The cytokines responsible include the inflammatory interleukins (IL) (e.g. IL-1 $\beta$, IL-6, IL-15, IL-17 and IL18 ), tumor necrosis factor-alpha (TNF- $\alpha$ ), and antiinflammatory interleukins (e.g. IL-4, IL-10 and IL-13) (Grover and Samson, 2016). The raise in IL-1 damages the articular cartilage, while TNF- $\alpha$ poses a similar effect and in synergy with IL-1 $\beta$ actions (Wojdasiewicz et al., 2014). The net outcome is the inhibition of the proteoglycan component production, which are the proteins that will bind the proteoglycans and type-II collagen in chondrocytes (Séguin and Bernier, 2003). The activated chondrocytes synthesize the matrix MMPs, such as MMP-1, MMP-3 and MMP-13 (Wojdasiewicz et al., 2014). Moreover, IL-6 exerts similar effects on the cartilage and in synergy with that of other inflammatory cytokines, resulting in reduced production of type-11 collagen and increased MMP activity (Porée et al., 2008). Both IL-1 $\beta$ and TNF- $\alpha$ also induce the synthesis of inflammatory mediators prostaglandin E2 (PGE2) and cyclooxygenase-2 (COX-2) (Kapoor et al., 2011).

Meanwhile, another cause which is the oxidative stress interrupts the cartilage homeostasis and leads to increased cartilage breakdown (Salimzadeh et al., 2018). Concurrently, reactive oxygen species (ROS) induce the synthesis of matrix-degrading enzymes and disrupt the matrix production (Im et al., 2007, 2008). Besides, IL-1 $\beta$ induces the synthesis of ROS-like peroxides and hydroxylated radicals, generation of nitric oxide (NO), and causes the insufficiency of superoxide dismutase (SOD) and catalase. The inadequacy of SOD causes an increased concentration of superoxide in which a reaction between NO and superoxide will produce peroxynitrite that consequently destroys the telomere by targeting guanine repeats in the DNA telomeres. This results in reduced collagen II production (Regan et al., 2008). Moreover, catalase reduction causes peroxide to accumulate, leading to increased lipid peroxidation due to the synthesis of 4-hydroxynonenal. 4-hydroxynonenal consequently increases the concentration of factors that stimulate collagen II breakdown and suppress its expression. Therefore, cartilage destruction will ensue in OA patients (Morquette et al., 2006).

Currently, there is no cure for OA, thus rendering its management to focus on symptom relief (Anandacoomarasamy and March, 2010), improvement of quality of life, and prevention of progression (Selten et al., 2017). Pain is the principal symptom among OA patients, with various evidence reporting the pain they experience to be related to inflammation and oxidative stress, cartilage destruction, and joint space narrowing (Andriacchi and Favre, 2014; Muraki et al., 2015). Thus, antioxidant and anti-inflammatory dietary supplements play a vital role to improve such symptoms. The mechanism of action of these dietary supplements can be explained based on the bioactive compounds present within them.

In this scoping review, the bioactive compounds found in the supplements which demonstrated positive impacts are predominantly polyphenols. Polyphenols are found abundantly in plants and vegetables, possessing strong anti-inflammatory and free radical scavenging antioxidant activity (González et al., 2011). Their antioxidant activity is influenced by the structure of the functional groups (Hussain et al., 2016), whereby the mechanism behind activities, such as radical scavenging and metal ion chelation, is dependent on the number of hydroxyl groups present (Kelly et al., 2002). Meanwhile, antioxidants can prevent OA progression by scavenging the ROS (Grover and Samson, 2016), retarding the enzymes involved in ROS production and upregulation or protection of antioxidant defenses (Mishra et al., 2013).

Whereas, the anti-inflammatory properties of phenolic compounds, such as flavonoids could are exhibited by suppressing PGE2 synthesis, COX-2 expression, and inducible microsomal prostaglandin $\mathrm{E}$ synthase-1 (mPGES-1) expression (Hämäläinen et al., 2011). This can lead to significant pain reduction among OA patients (Bensen et al., 1999). Besides, pain relief is attributed to the anti-nociceptive activity of flavonoid and tannin (Ghogare et al., 2009). In vitro and in vivo studies have reported that phenolic compounds can delay OA development and progression by altering the related metabolic and biochemical processes, including suppressing the synthesis of pro-inflammatory cytokines, such as IL-1 $\beta$, IL-6, TNF- $\alpha$ and PGE2 in the affected joints (Murakami et al., 2007; Ahmed, 2010). In addition, flavonoids examined in vivo inhibit inducible NO synthase, suppress NO production and neutralize other reactive nitrogen species (RNS) and ROS-like superoxide (Adhikari et al., 2011) involved in inducing inflammatory gene expression (Tseng-Crank et al., 
2010).

Next, the long chain omega-3 polyunsaturated fatty acids (PUFAs) such as eicosapentaenoic acid (EPA) and docosahexaenoic acid (DHA) are also the bioactive ingredient responsible for its beneficial effects. Both of these fatty acids exert anti-inflammatory effect by inhibiting the inflammatory genes expression via the suppression of pro-inflammatory transcription factor nuclear factor kappa B (Calder, 2015). Besides, Lcarnitine showed the anti-inflammatory activity by lowering the inflammatory factors such as IL-1 $\beta$ which subsequently lead to pain reduction and physical function improvement (Malek Mahdavi et al., 2016). In addition, 3-O-acetyl-11-keto-beta-boswellic acid (AKBA), the active ingredient of BSE is a powerful inhibitor of 5-lipoxygenase (5-LOX) activity (Suva et al., 2017) which can reduce pain and inflammation associated with OA (Suva et al., 2018).

Moreover, ASU is the remaining oily extracts derived from the soap production which contain phytosterols, triterpenoids and lipophilic vitamins (Goudarzi et al., 2018). ASU can minimize PGE2 and NO production which related to pain and inflammation (Goudarzi et al., 2017). CFB is a patented complex of boron, fructose and calcium found ubiquitous in plants (Reyes-Izquierdo et al., 2012). CFB can reduce serum levels of C-reactive protein (CRP) which associated with inflammation-related conditions such as OA (Scorei and Scorei, 2013). Ganglioside derived from DBE can inhibit the expression of MMPs in IL-1 $\beta$-induced OA which stimulate the accumulation of type II collagen (Suh et al., 2016).

While this scoping review provides the best evidence regarding the effectiveness of specific pharmacological treatments when assessing single supplements or supplements with similar chemical components, it should be interpreted with caution due to several limitations (Freedman, 1990). For most of the supplements examined, the number of studies conducted for each supplement is relatively small with a maximum of four studies in clinical trials involving ginger and curcumin supplementation, respectively. Secondly, most of the studies provided information on knee OA, thus reducing the concluding generalizability for other types of OA. Furthermore, more than half of the studies were followed up in short term duration ( $\leq$ three months), thereby rendering the efficacy of these supplements in medium and long term durations as uncertain. Hence, it is necessary to carry out RCTs having a longer intervention duration to further confirm the efficacy of these supplements. Moreover, it is noticed that there was unequal gender distribution in most of the studies in which there were more female participants compared to male participants. This might be due to the fact that women had a higher risk of getting OA compared to men which result in higher OA incidence among women. This was attributable by the estrogen deficiency particularly after menopause (Venkatachalam et al., 2018). Last but not least, the biochemical parameters and safety issues of these supplements were not investigated.

\section{Conclusion}

Overall, out of the 24 dietary supplements identified, most of them demonstrated beneficial effects on the clinical signs and symptoms. These dietary supplements were krill oil, ASU, curcumin, BSE, Pycnogenol, PFP extract, L-carnitine, ART, DBE, garlic, Momordica charantia, argan oil, ginger, PJ, sesame seed, Phytalgic $\AA$, soy protein and CFB. In contrast, Aquamin supplementation did not exert positive impacts on OA management, while inconsistent findings were observed in the case of GLM extract, vitamin E, MSM, LFO, ginger, willow bark extract and rose hip supplementation. Since this scoping review noticed that there was very limited study which explored the efficacy of antioxidant and anti-inflammatory dietary supplements to manage OA in Association of Southeast Asian Nations (ASEAN) countries. Hence, future researchers need to collaborate and address this identified gap by examining the effectiveness of these supplements towards OA patients among ASEAN populations.

\section{Conflict of Interest}

The authors declare no conflict of interest.

\section{Acknowledgements}

This work was funded by the Fundamental Research Grant Scheme (FRGS/1/2018/TK02/UNISZA/03/1). The authors would like to extend their gratitude to everyone who helped in the article writing process.

\section{References}

Adhikari, S., Tilak, J.C. and Devasagayam, T.P.A. (2011). Free radical reactions of a naturally occurring flavone baicalein and possible mechanisms towards its membrane protective properties. Indian Journal of Biochemistry and Biophysics, 48(4), 275282.

Ahmed, S. (2010). Green tea polyphenol epigallocatechin 3-gallate in arthritis: progress and promise. Arthritis Research and Therapy, 12(2), 208. https://doi.org/10.1186/ar2982 
Alipour, Z., Asadizaker, M., Fayazi, S., Yegane, N., Kochak, M. and Haghighi Zadeh, M.H. (2016). The Effect of Ginger on Pain and Satisfaction of Patients with Knee Osteoarthritis. Jundishapur Journal of Chronic Disease Care, 6(1), e34798. https:// doi.org/10.17795/jjcdc-34798

Altman, R.D. and Marcussen, K.C. (2001). Effects of a ginger extract on knee pain in patients with osteoarthritis. Arthritis and Rheumatism, 44(11), 2531-2538. https://doi.org/10.1002/1529-0131 (200111)44:11<2531::AID-ART433>3.0.CO;2-J

Anandacoomarasamy, A. and March, L. (2010). Current evidence for osteoarthritis treatments. Therapeutic Advances in Musculoskeletal Disease, 2(1), 17-28. https://doi.org/10.1177/1759720X09359889

Andriacchi, T.P. and Favre, J. (2014). The Nature of In Vivo Mechanical Signals That Influence Cartilage Health and Progression to Knee Osteoarthritis. Current Rheumatology Reports, 16(11), 1-8. https:// doi.org/10.1007/s11926-014-0463-2

Appelboom, T., Schuermans, J., Verbruggen, G., Henrotin, Y. and Reginster, J.Y. (2001). Symptoms modifying effect of avocado/soybean unsaponifiables (ASU) in knee osteoarthritis: A double blind, prospective, placebo-controlled study. Scandinavian Journal of Rheumatology, 30(4), 242247. https://doi.org/10.1080/030097401316909602

Arjmandi, B.H., Khalil, D.A., Lucas, E.A., Smith, B.J., Sinichi, N., Hodges, S.B., Juma, S., Munson, M.E., Payton, M.E., Tivis, R.D. and Svanborg, A. (2004). Soy protein may alleviate osteoarthritis symptoms. Phytomedicine, 11(7-8), 567-575. https:// doi.org/10.1016/j.phymed.2003.11.001

Arksey, H. and O'Malley, L. (2005). Scoping studies: towards a methodological framework. International Journal of Social Research Methodology, 8(1), 1932. https://doi.org/10.1080/1364557032000119616

Ashford, S. and Williard, J. (2014). Osteoarthritis: A review. Nurse Practitioner, 39(5), 1-8. https:// doi.org/10.1097/01.NPR.0000445886.71205.c4

Belcaro, G., Cesarone, M.R., Dugall, M., Pellegrini, L., Ledda, A., Grossi, M.G., Togni, S. and Appendino, G. (2010). Efficacy and safety of Meriva ${ }^{\circledR}$, a curcumin-phosphatidylcholine complex, during extended administration in osteoarthritis patients. Alternative Medicine Review, 15(4), 337-344. Retrieved from http:// archive.foundationalmedicinereview.com/ publications/15/4/337.pdf

Belcaro, G., Cesarone, M.R., Errichi, S., Zulli, C., Errichi, B.M., Vinciguerra, G., Ledda, A., Di Renzo, A., Stuard, M., Dugall, M., Pellegrini, L., Errichi, S.,
Gizzi, G., Ippolito, E., Ricci, A., Cacchio, M., Cipollone, G., Ruffini, I., Fani, F., Hosoi, M. and Rohdewald, P. (2008a). Treatment of osteoarthritis with Pycnogenol ${ }^{\circledR}$. The SVOS (San Valentino osteoarthrosis study). evaluation of signs, symptoms, physical performance and vascular aspects. Phytotherapy Research, 22(4), 518-523. https:// doi.org/10.1002/ptr.2376

Belcaro, G., Cesarone, M. R., Errichi, S., Zulli, C., Errichi, B. M., Vinciguerra, G., Ledda, A., Di Renzo, A., Stuard, M., Dugall, M., Pellegrini, L., Errichi, S., Gizzi, G., Ippolito, E., Ricci, A., Cacchio, M., Cipollone, G., Ruffini, I., Fani, F., Hosoi, M. and Rohdewald, P. (2008b). Variations in C-reactive protein, plasma free radicals and fibrinogen values in patients with osteoarthritis treated with Pycnogenol ${ }^{\circledR}$. Redox Report, 13(6), 271-276. https:// doi.org/10.1179/135100008X309019

Bensen, W.G., Fiechtner, J.J., Mcmillen, J.I., Zhao, W.W., Yu, S.S., Woods, E.M., Hubbard, R.C., Isakson, P.C., Verburg, K.M. and Steven Geis, G. (1999). Treatment of osteoarthritis with celecoxib, a cyclooxygenase-2 inhibitor: A randomized controlled trial. Mayo Clinic Proceedings, 74(11), 1095-1105. https://doi.org/10.4065/74.11.1095

Bijlsma, J.W.J., Berenbaum, F. and Lafeber, F.P.J.G. (2011). Osteoarthritis: An update with relevance for clinical practice. The Lancet, 377(9783), 2115-2126. https://doi.org/10.1016/S0140-6736(11)60243-2

Birrell, F.N. and Oliver, S. (2010). Osteoarthritis in primary care. Practice Nurse, 39(2), 38-45.

Brand, C., Snaddon, J., Bailey, M. and Cicuttini, F. (2001). Vitamin E is ineffective for symptomatic relief of knee osteoarthritis: A six month double blind, randomised, placebo controlled study. Annals of the Rheumatic Diseases, 60(10), 946-949. https:// doi.org/10.1136/ard.60.10.946

Calder P.C. (2015). Marine omega-3 fatty acids and inflammatory processes: Effects, mechanisms and clinical relevance. Biochimica et Biophysica Acta (BBA) - Molecular and Cell Biology of Lipids, 1851 (4), 469-484. https://doi.org/10.1016/ j.bbalip.2014.08.010

Chin, K.Y. and Ima-Nirwana, S. (2018). The role of vitamin $\mathrm{E}$ in preventing and treating osteoarthritis A review of the current evidence. Frontiers in Pharmacology, 9, 946. https://doi.org/10.3389/ fphar.2018.00946

Cisár, P., Jány, R., Waczulíková, I., Sumegová, K., Muchová, J., Vojtaššák, J., Duuraćková, Z., Lisý, M. and Rohdewald, P. (2008). Effect of pine bark extract (Pycnogenol®) on symptoms of knee osteoarthritis. Phytotherapy Research, 22(8), 1087- 
1092. https://doi.org/10.1002/ptr.2461

Conaghan, P., Porcheret, M., Kingsbury, S.R. Gammon, A., Soni, A., Hurley, M., Rayman, M.P., Barlow, J., Hull, R.G., Cumming, J., Llewelyn, K., Moscogiuri, F., Lyons, J. and Birrel, F. (2014). Impact and therapy of osteoarthritis: the Arthritis Care OA Nation 2012 survey. Clinical Rheumatology, 9, 1581 -1588. https://doi.org/10.1007/s10067-014-2692-1

da Costa, B.R., Reichenbach, S., Keller, N., Nartey, L., Wandel, S., Jüni, P. and Trelle, S. (2017). Effectiveness of non-steroidal anti-inflammatory drugs for the treatment of pain in knee and hip osteoarthritis: a network meta-analysis. The Lancet, 390(10090), e21-e33. https://doi.org/10.1016/S0140 $-6736(17) 31744-0$

Debbi, E.M., Agar, G., Fichman, G., Ziv, Y.B., Kardosh, R., Halperin, N., Elbaz, A., Beer, Y. and Debi, R. (2011). Efficacy of methylsulfonylmethane supplementation on osteoarthritis of the knee: a randomized controlled study. BMC Complementary and Alternative Medicine, 11, 50. https:// doi.org/10.1186/1472-6882-11-50

Dehghani, S., Alipoor, E., Salimzadeh, A., Yaseri, M., Hosseini, M., Feinle-Bisset, C. and HosseinzadehAttar, M.J. (2018). The effect of a garlic supplement on the pro-inflammatory adipocytokines, resistin and tumor necrosis factor-alpha, and on pain severity, in overweight or obese women with knee osteoarthritis. Phytomedicine, 48, 70-75. https://doi.org/10.1016/ j.phymed.2018.04.060

Doherty, M., Hunter, D.J., Bijlsma, H., Arden, N. and Dalbeth, N. (Eds.) (2016). Oxford Textbook of Osteoarthritis and Crystal Arthropathy. Vol. 1. United Kingdom: Oxford University Press. https:// doi.org/10.1093/med/9780199668847.001.0001

Eftekhar Sadat, B., Khadem Haghighian, M., Alipoor, B., Malek Mahdavi, A., Asghari Jafarabadi, M., and Moghaddam, A. (2013). Effects of sesame seed supplementation on clinical signs and symptoms in patients with knee osteoarthritis. International Journal of Rheumatic Diseases, 16(5), 578-582. https://doi.org/10.1111/1756-185X.12133

Essouiri, J., Harzy, T., Benaicha, N., Errasfa, M. and Abourazzak, F.E. (2017). Effectiveness of Argan Oil Consumption on Knee Osteoarthritis Symptoms: A Randomized Controlled Clinical Trial. Current Rheumatology Reviews, 13(3), 231-235. https:// doi.org/10.2174/1573397113666170710123031

Farid, R., Mirfeizi, Z., Mirheidari, M., Rezaieyazdi, Z., Mansouri, H., Esmaelli, H., Zibadi, S., Rohdewald, P. and Watson, R.R. (2007). Pycnogenol supplementation reduces pain and stiffness and improves physical function in adults with knee osteoarthritis. Nutrition Research, 27(11), 692-697. https://doi.org/10.1016/j.nutres.2007.09.007

Farid, R., Rezaieyazdi, Z., Mirfeizi, Z., Hatef, M.R., Mirheidari, M., Mansouri, H., Esmaelli, H., Bentley, G., Lu, Y., Foo, Y. and Watson, R.R. (2010). Oral intake of purple passion fruit peel extract reduces pain and stiffness and improves physical function in adult patients with knee osteoarthritis. Nutrition Research, 30(9), 601-606. https://doi.org/10.1016/ j.nutres.2010.08.010

Freedman, B. (1990). Placebo-controlled trials and the logic of clinical purpose. IRB: Ethics and Human Research, 12(6), 1-6. https:// doi.org/10.2307/3564541

Frestedt, J.L., Kuskowski, M.A., and Zenk, J.L. (2009). A natural seaweed derived mineral supplement (Aquamin F) for knee osteoarthritis: A randomised, placebo controlled pilot study. Nutrition Journal, 8 (1), 7. https://doi.org/10.1186/1475-2891-8-7

Ghogare, U.R., Nirmal, S.A., Patil, R.Y. and Kharya, M.D. (2009). Antinociceptive activity of Gynandropsis gynandra leaves. Natural Product Research, 23(4), 327-333. https:// doi.org/10.1080/14786410802047862

Ghoochani, N., Karandish, M., Mowla, K., Haghighizadeh, M.H. and Jalali, M.T. (2016). The effect of pomegranate juice on clinical signs, matrix metalloproteinases and antioxidant status in patients with knee osteoarthritis. Journal of the Science of Food and Agriculture, 96(13), 4377-4381. https:// doi.org/10.1002/jsfa.7647

Ginnerup-Nielsen, E., Christensen, R., Bliddal, H., Zangger, G., Hansen, L. and Henriksen, M. (2015). Improved gait in persons with knee related mobility limitations by a rosehip food supplement: A randomized, double-blind, placebo-controlled trial. Gait and Posture, 42(3), 340-347. https:// doi.org/10.1016/j.gaitpost.2015.07.001

González, R., Ballester, I., López-Posadas, R., Suárez, A., Zarzuelo, O., Martinez-Augustin, O. and Sanchez De Medina, F. (2011). Effects of Flavonoids and other Polyphenols on Inflammation. Critical Reviews in Food Science and Nutrition, 51(4), 331-362. https://doi.org/10.1080/10408390903584094

Goudarzi, R., Reid, A. and McDougall, J.J. (2018). Evaluation of the novel avocado/soybean unsaponifiable Arthrocen to alter joint pain and inflammation in a rat model of osteoarthritis. PLoS ONE, 13(2), 1-9. https://doi.org/10.1371/ journal.pone.0191906

Goudarzi, R., Taylor, J.F., Yazdi, P.G. and Pedersen, B.A. (2017). Effects of Arthrocen, an avocado/soy 
unsaponifiables agent, on inflammatory mediators and gene expression in human chondrocytes. FEBS Open Bio, 7(2), 187-194. https:// doi.org/10.1002/2211-5463.12176

Green, J.A., Hirst-Jones, K.L., Davidson, R.K., Jupp, O., Bao, Y., MacGregor, A.J., Donell, S.T., Cassidy, A. and Clark, I.M. (2014). The potential for dietary factors to prevent or treat osteoarthritis. Proceedings of the Nutrition Society, 73(2), 278-288. https:// doi.org/10.1017/S0029665113003935

Grover, A.K. and Samson, S.E. (2016). Benefits of antioxidant supplements for knee osteoarthritis: Rationale and reality. Nutrition Journal, 15(1), 1. https://doi.org/10.1186/s12937-015-0115-z

Hämäläinen, M., Nieminen, R., Asmawi, M.Z., Vuorela, P., Vapaatalo, H. and Moilanen, E. (2011). Effects of flavonoids on prostaglandin E2 production and on COX-2 and mPGES-1 expressions in activated macrophages. Planta Medica, 77(13), 1504-1511. https://doi.org/10.1055/s-0030-1270762

Hunt, S., Stebbings, S. and McNamara, D. (2016). An open-label six-month extension study to investigate the safety and efficacy of an extract of Artemisia annua for managing pain, stiffness and functional limitation associated with osteoarthritis of the hip and knee. The New Zealand Medical Journal, 129 (1444), 97-102. https://doi.org/10.1007/s10067-0153110-z

Hussain, T., Tan, B., Yin, Y., Blachier, F., Tossou, M.C.B. and Rahu, N. (2016). Oxidative Stress and Inflammation: What Polyphenols Can Do for Us? Oxidative Medicine and Cellular Longevity, 2016, 19. https://doi.org/10.1155/2016/7432797

Im, H.J., Li, X., Muddasani, P., Kim, G.H., Davis, F., Rangan, J., Forsyth, C.B., Ellman, M. and Thonar, E. J.M.A. (2008). Basic fibroblast growth factor accelerates matrix degradation via a neuro-endocrine pathway in human adult articular chondrocytes. Journal of Cellular Physiology, 215(2), 452-463. https://doi.org/10.1002/jcp.21317

Im, H.J., Muddasani, P., Natarajan, V., Schmid, T.M., Block, J.A., Davis, F., Van Wijnen, A.J. and Loeser, R.F. (2007). Basic fibroblast growth factor stimulates matrix metalloproteinase-13 via the molecular cross-talk between the mitogen-activated protein kinases and protein kinase $\mathrm{C} \delta$ pathways in human adult articular chondrocytes. Journal of Biological Chemistry, 282(15), 11110-11121. https://doi.org/10.1074/jbc.M609040200

Jacquet, A., Girodet, P.-O., Pariente, A., Forest, K., Mallet, L. and Moore, N. (2009). Phytalgic, a food supplement, vs placebo in patients with osteoarthritis of the knee or hip: a randomised double-blind placebo-controlled clinical trial. Arthritis Research and Therapy, 11(6), R192. https://doi.org/10.1186/ ar2891

Kapoor, M., Martel-Pelletier, J., Lajeunesse, D., Pelletier, J.P. and Fahmi, H. (2011). Role of proinflammatory cytokines in the pathophysiology of osteoarthritis. Nature Reviews Rheumatology, 7(1), 33-42. https://doi.org/10.1038/nrrheum.2010.196

Kim, L.S., Axelrod, L.J., Howard, P., Buratovich, N. and Waters, R.F. (2006). Efficacy of methylsulfonylmethane (MSM) in osteoarthritis pain of the knee: A pilot clinical trial. Osteoarthritis and Cartilage, 14(3), 286-294. https://doi.org/10.1016/ j.joca.2005.10.003

Kinoshita, T., Matsumoto, A., Yoshino, K. and Furukawa, S. (2017). The effects of licorice flavonoid oil with respect to increasing muscle mass: a randomized, double-blind, placebo-controlled trial. Journal of the Science of Food and Agriculture, 97 (8), 2339-2345. https://doi.org/10.1002/jsfa.8044

Lau, C.S., Chiu, P.K.Y., Chu, E.M.Y., Cheng, I.Y.W., Tang, W.M., Man, R.Y.K. and Halpern, G.M. (2004). Treatment of knee osteoarthritis with Lyprinol ${ }^{\circledR}$, lipid extract of the green-lipped mussel A double-blind placebo-controlled study. Progress in Nutrition, 6(1), 17-31.

Lei, M., Guo, C., Wang, D., Zhang, C. and Hua, L. (2017). The effect of probiotic Lactobacillus casei Shirota on knee osteoarthritis: A randomised doubleblind, placebo-controlled clinical trial. Beneficial Microbes, 8(5), 697-703. https://doi.org/10.3920/ BM2016.0207

Lim, S.M., Zulkefl, Is., Amran, A.S., Azidah, A.K. and Md Rizman, M.L. (2018). The effects of Momordica charantia (bitter melon) supplementation in patients with primary knee osteoarthritis: A single-blinded, randomized controlled trial. Complementary Therapies in Clinical Practice, 32, 181-186. https:// doi.org/10.1016/j.ctcp.2018.06.012

Liu, X., Machado, G.C., Eyles, J.P., Ravi, V. and Hunter, D.J. (2018). Dietary supplements for treating osteoarthritis: A systematic review and metaAnalysis. British Journal of Sports Medicine, 52(3), 167-175. https://doi.org/10.1136/bjsports-2016097333

Malek Mahdavi, A., Mahdavi, R. and Kolahi, S. (2016). Effects of 1-Carnitine Supplementation on Serum Inflammatory Factors and Matrix Metalloproteinase Enzymes in Females with Knee Osteoarthritis: A Randomized, Double-Blind, Placebo-Controlled Pilot Study. Journal of the American College of Nutrition, 35(7), 597-603. https:// doi.org/10.1080/07315724.2015.1068139 
Malek Mahdavi, A., Mahdavi, R., Kolahi, S., Zemestani, M. and Vatankhah, A.M. (2015). L-Carnitine supplementation improved clinical status without changing oxidative stress and lipid profile in women with knee osteoarthritis. Nutrition Research, 35(8), 707-715.

https://doi.org/10.1016/

j.nutres.2015.06.003

Ministry of Health Malaysia. (2013). CPG Management of Osteoarthritis. $2^{\text {nd }}$ ed. Malaysia: Malaysia Health Technology Assessment Section (MaHTAS). Retrieved December 28, 2018 from website: http:// www.moh.gov.my/index.php/file_manager/ dl_item/625746726248567459585167644756796132 6c7561533945636d466d6446394455456466543045 $756347526 \mathrm{~d}$

Mishra, A., Sharma, A.K., Kumar, S., Saxena, A.K., and Pandey, A.K. (2013). Bauhinia variegata leaf extracts exhibit considerable antibacterial, antioxidant, and anticancer activities. BioMed Research International, 2013, 1-10. https:// doi.org/10.1155/2013/915436

Moher, D., Liberati, A., Tetzlaff, J. and Altman, D.G. (2009). Preferred Reporting Items for Systematic Reviews and Meta-Analyses: The PRISMA Statement. Annals of Internal Medicine, 151(4), 264. https://doi.org/10.7326/0003-4819-151-4-200908180 $-00135$

Morquette, B., Shi, Q., Lavigne, P., Ranger, P., Fernandes, J.C. and Benderdour, M. (2006). Production of lipid peroxidation products in osteoarthritic tissues: New evidence linking 4hydroxynonenal to cartilage degradation. Arthritis and Rheumatism, 54(1), 271-281. https:// doi.org/10.1002/art.21559

Murakami, A., Song, M., Katsumata, S., Uehara, M., Suzuki, K. and Ohigashi, H. (2007). Citrus nobiletin suppresses bone loss in ovariectomized ddY mice and collagen-induced arthritis in $\mathrm{DBA} / 1 \mathrm{~J}$ mice: Possible involvement of receptor activator of NF- $\kappa \mathrm{B}$ ligand (RANKL)-induced osteoclastogenesis regulation. Biofactors, 30, 179-192. https:// doi.org/10.1002/biof.5520300305

Muraki, S., Akune, T., En-yo, Y., Yoshida, M., Suzuki, T., Yoshida, H., Ishibashi, H., Tokimura, F., Yamamoto, S., Tanaka, S., Nakamura, K., Kawaguchi, H., Oka, H. and Yoshimura, N. (2015). Joint space narrowing, body mass index, and knee pain: The ROAD study (OAC1839R1). Osteoarthritis and Cartilage, 23(6), 874-881. https://doi.org/10.1016/j.joca.2015.01.011

Nakagawa, Y., Mukai, S., Yamada, S., Matsuoka, M., Tarumi, E., Hashimoto, T., Tamura, C., Imaizumi, A., Nishihira, J. and Nakamura, T. (2014). Short- term effects of highly-bioavailable curcumin for treating knee osteoarthritis: a randomized, doubleblind, placebo-controlled prospective study. Journal of Orthopaedic Science, 19(6), 933-939. https:// doi.org/10.1007/s00776-014-0633-0

Neogi, T. and Zhang, Y. (2013). Epidemiology of osteoarthritis. Rheumatic Diseases Clinics of North America, 39(1), 1-19. https://doi.org/10.1016/ j.rdc.2012.10.004

Niempoog, S., Pawa, K.K. and Amatyakul, C. (2012). The efficacy of powdered ginger in osteoarthritis of the knee. Journal of the Medical Association of Thailand, 95(Suppl. 1), S59-S64.

Nur Aimi, A.Z, Sakinah. H, Noor Aini, M.Y and Nurulhuda M.H. (2018). Health-related quality of life among knee and hip osteoarthritis patients in Kuala Nerus, Terengganu. Malaysian Dietitians' Association - National Conference 2018, 25th - 26th June 2018. Malaysia: Perstuan Dietitian Malaysia.

Panahi, Y., Rahimnia, A.R., Sharafi, M., Alishiri, G., Saburi, A. and Sahebkar, A. (2014). Curcuminoid treatment for knee osteoarthritis: A randomized double-blind placebo-controlled trial. Phytotherapy Research, 28(11), 1625-1631. https:// doi.org/10.1002/ptr.5174

Philp, A.M., Davis, E.T. and Jones, S.W. (2016). Developing anti-inflammatory therapeutics for patients with osteoarthritis. Rheumatology (United Kingdom), 56(6), 869-881. https://doi.org/10.1093/ rheumatology/kew278

Pietrzkowski, Z., Phelan, M.J., Keller, R., Shu, C., Argumedo, R. and Reyes-Izquierdo, T. (2014). Short -term efficacy of calcium fructoborate on subjects with knee discomfort: A comparative, double-blind, placebo-controlled clinical study. Clinical Interventions in Aging, 9, 895-899. https:// doi.org/10.2147/CIA.S64590

Porée, B., Kypriotou, M., Chadjichristos, C., Beauchef, G., Renard, E., Legendre, F., Melin, M., Gueret, S., Hartmann, D.J., Malléin-Gerin, F., Pujol, J.P., Boumediene, K. and Galéra, P. (2008). Interleukin-6 (IL-6) and/or soluble IL-6 receptor down-regulation of human type II collagen gene expression in articular chondrocytes requires a decrease of Sp1.Sp3 ratio and of the binding activity of both factors to the COL2A1 promoter. Journal of Biological Chemistry, 283(8), 4850-4865. https:// doi.org/10.1074/jbc.M706387200

Regan, E.A., Bowler, R.P. and Crapo, J.D. (2008). Joint fluid antioxidants are decreased in osteoarthritic joints compared to joints with macroscopically intact cartilage and subacute injury. Osteoarthritis and Cartilage, 16(4), 515-521. https://doi.org/10.1016/ 
j.joca.2007.09.001

Reyes-Izquierdo, T., Nemzer, B., Gonzalez, A. E., Zhou, Q., Argumedo, R., Shu, C. and Pietrzkowski, Z. (2012). Short-term Intake of Calcium Fructoborate Improves WOMAC and McGill Scores and Beneficially Modulates Biomarkers Associated with Knee Osteoarthritis: A Pilot Clinical Double-blinded Placebo-controlled Study. American Journal of Biomedical Sciences, 2012(2), 111-122. https:// doi.org/10.5099/aj120200111

Rosenbaum, C.C., O’Mathúna, D.P., Chavez, M. and Shields, K. (2010). Antioxidants and antiinflammatory dietary supplements for osteoarthritis and rheumatoid arthritis. Alternative Therapies in Health and Medicine, 16(2), 32-40.

Salimzadeh, A., Alipoor, E., Dehghani, S., Yaseri, M., Hosseini, M., Feinle-Bisset, C. and HosseinzadehAttar, M.J. (2018). The effect of 12-week garlic supplementation on symptom relief in overweight or obese women with knee osteoarthritis. International Journal of Clinical Practice, 72(6), 1-7. https:// doi.org/10.1111/ijcp.13208

Schmid, B., Lüdtke, R., Selbmann, H.K., Kötter, I., Tschirdewahn, B., Schaffner, W. and Heide, L. (2001). Efficacy and tolerability of a standardized willow bark extract in patients with osteoarthritis: Randomized placebo-controlled, double blind clinical trial. Phytotherapy Research, 15(4), 344350. https://doi.org/10.1002/ptr.981

Scorei, I.D. and Scorei, R.I. (2013). Calcium fructoborate helps control inflammation associated with diminished bone health. Biological Trace Element Research, 155(3), 315-321. https:// doi.org/10.1007/s12011-013-9800-y

Séguin, C.A. and Bernier, S.M. (2003). TNFalpha suppresses link protein and type II collagen expression in chondrocytes: Role of MEK $1 / 2$ and NF -kappaB signaling pathways. Journal of Cellular Physiology, 197(3), 356-369. https:// doi.org/10.1002/jcp.10371

Selten, E.M.H., Vriezekolk, J.E., Schers, H.J., Nijhof, M.W., Van Der Laan, W.H., Van Der MeulenDIlling, R.G., Roelien G., Geenen, R. and Van Den Ende, C.H.M. (2017). Development of the "treatment beliefs in knee and hip OsteoArthritis (TOA)" questionnaire. BMC Musculoskeletal Disorders, 18(1), 402. https://doi.org/10.1186/ s12891-017-1762-3

Sengupta, K., Alluri, K.V, Satish, A.R., Mishra, S., Golakoti, T., Sarma, K.V. Dey, D. and Raychaudhuri, S. P. (2008). A double blind, randomized, placebo controlled study of the efficacy and safety of 5-Loxin ${ }^{\circledR}$ for treatment of osteoarthritis of the knee. Arthritis Research and Therapy, 10(4), R85. https://doi.org/10.1186/ar2461

Sengupta, K., Krishnaraju, A.V., Vishal, A.A., Mishra, A., Trimurtulu, G., Sarma, K.V.S., Raychaudhuri, S. K. and Raychaudhuri, S.P. (2010). Comparative efficacy and tolerability of 5-Loxin ${ }^{\circledR}$ and Aflapin ${ }^{\circledR a g a i n s t ~ o s t e o a r t h r i t i s ~ o f ~ t h e ~ k n e e: ~ A ~ d o u b l e ~}$ blind, randomized, placebo controlled clinical study. International Journal of Medical Sciences, 7(6), 366 -377. https://doi.org/10.7150/ijms.7.366

Shin, D., Kim, E.A., Kim, Y.Y., Kim, M.S., Kim, J.H., Ahn, C.W., Park, S.H., Lee, K.W., Kim, J.H. and Kim, J.Y. (2018). Deer Bone Extract Supplementation for Mild-to-Moderate Knee Osteoarthritis Symptoms: A Randomized, DoubleBlind, Placebo-Controlled Trial. Journal of Medicinal Food, 21(2), 159-166. https:// doi.org/10.1089/jmf.2017.4023

Srivastava, S., Saksena, A.K., Khattri, S., Kumar, S., and Dagur, R.S. (2016). Curcuma longa extract reduces inflammatory and oxidative stress biomarkers in osteoarthritis of knee: a four-month, double-blind, randomized, placebo-controlled trial. Inflammopharmacology, 24(6), 377-388. https:// doi.org/10.1007/s10787-016-0289-9

Stebbings, S., Gray, A., Schneiders, A.G. and Sansom, A. (2017). A randomized double-blind placebocontrolled trial to investigate the effectiveness and safety of a novel green-lipped mussel extract BioLex ${ }^{\circledR}$-for managing pain in moderate to severe osteoarthritis of the hip and knee. $B M C$ Complementary and Alternative Medicine, 17(1), 416. https://doi.org/10.1186/s12906-017-1907-9

Suh, H.J., Lee, H., Min, B.J., Jung, S.U., and Jung, E.Y. (2016). Effects of gangliosides from deer bone extract on the gene expressions of matrix metalloproteinases and collagen type II in interleukin $-1 \beta$-induced osteoarthritic chondrocytes. Nutrition Research and Practice, 10(6), 569-574. https:// doi.org/10.4162/nrp.2016.10.6.569

Suva, M., Kheni, D. and Sureja, V. (2018). Aflapin ${ }^{\circledR}$ : A novel and selective 5-lipoxygenase inhibitor for arthritis management. Indian Journal of Pain, 32(1), 16. https://doi.org/10.4103/ijpn.ijpn_71_17

Suva, M.A., Kheni, D.B. and Sureja, V.P. (2017). Management strategies for knee osteoarthritis: Aflapin ${ }^{\circledR}$ (Boswellia serrata extract). Ayu, 38(1-2), 94. https://doi.org/10.4103/ayu.AYU_203_17

Suzuki, Y., Fukushima, M., Sakuraba, K., Sawaki, K. and Sekigawa, K. (2016). Krill oil improves mild knee joint pain: A randomized control trial. PLoS ONE, 11(10), e0162769. https://doi.org/10.1371/ journal.pone.0162769 
Tantavisut, S., Tanavalee, A., Honsawek, S., Suantawee, T., Ngarmukos, S., Adisakwatana, S. and Callaghan, J.J. (2017). Effect of vitamin $\mathrm{E}$ on oxidative stress level in blood, synovial fluid, and synovial tissue in severe knee osteoarthritis: a randomized controlled study. BMC Musculoskeletal Disorders, 18(1), 281. https://doi.org/10.1186/s12891-017-1637-7

Tseng-Crank, J., Sung, S., Jia, Q., Zhao, Y., Burnett, B., Park, D.R. and Woo, S.S. (2010). A medicinal plant extract of scutellaria baicalensis and acacia catechu reduced LPS-stimulated gene expression in immune cells: A comprehensive genomic study using QPCR, ELISA, and microarray. Journal of Dietary Supplements, 7(3), 253-272. https:// doi.org/10.3109/19390211.2010.493169

Venkatachalam, J., Natesan, M., Eswaran, M., Johnson, A.K.S., Bharath, V. and Singh, Z. (2018). Prevalence of osteoarthritis of knee joint among adult population in a rural area of Kanchipuram district, Tamil Nadu. Indian Journal of Public Health, 61(2), 117-122. http://doi.org/10.4103/ijph.IJPH

Vishal, A.A., Mishra, A. and Raychaudhuri, S.P. (2011). A double blind, randomized, placebo controlled clinical study evaluates the early efficacy of Aflapin ${ }^{\circledR}$ in subjects with osteoarthritis of knee. International Journal of Medical Sciences, 8(7), 615 -622. https://doi.org/10.7150/ijms.8.615

Warholm, O., Skaar, S., Hedman, E., Mølmen, H.M. and Eik, L. (2003). The effects of a standardized herbal remedy made from a subtype of Rosa canina in patients with osteoarthritis: A double-blind, randomized, placebo-controlled clinical trial. Current Therapeutic Research - Clinical and Experimental, 64(1), 21-31. https://doi.org/10.1016/ S0011-393X(03)00004-3

Wojdasiewicz, P., Poniatowski, Ł.A. and Szukiewicz, D. (2014). The role of inflammatory and antiinflammatory cytokines in the pathogenesis of osteoarthritis. Mediators of Inflammation, 2014, 119. https://doi.org/10.1155/2014/561459

Woolf, A.D. and Pfleger, B. (2003). Burden of major musculoskeletal conditions. Bulletin of the World Health Organization, 81(9), 646-56.

Zakeri, Z., Izadi, S., Bari, Z., Soltani, F., Narouie, B. and Ghasemi-Rad, M. (2011). Evaluating the effects of ginger extract on knee pain, stiffness and difficulty in patients with knee osteoarthritis. Journal of Medicinal Plants Research, 5(15), 3375-3379. Retrieved from http://www.academicjournals.org/ JMPR

Zhang, Y. and Jordan, J.M. (2010). Epidemiology of osteoarthritis. Clinics in Geriatric Medicine, 26(3), 355-369. https://doi.org/10.1016/j.cger.2010.03.001 